\title{
Rhabdias filicaudalis n. sp. (Nematoda: Rhabdiasidae) from the snake Spilotes pullatus (Serpentes: Colubridae) in Brazil
}

\author{
T.H. Barrella ${ }^{1 *}$, K.R. dos Santos ${ }^{2}$ and R.J. da Silva ${ }^{1}$ \\ ${ }^{1}$ Department of Parasitology, Instituto de Biociências, Universidade \\ Estadual Paulista, Botucatu, São Paulo State, Brazil: ${ }^{2}$ Departament of \\ Veterinary Medicine, Universidade Federal do Piauí, Bom Jesus, \\ Piauí State, Brazil
}

(Accepted 26 October 2009; First Published Online 24 November 2009)

\begin{abstract}
Rhabdias filicaudalis n. sp. (Nematoda: Rhabdiasidae) from the lung of Spilotes pullatus (Serpentes: Colubridae) is described. The host snake was captured in the municipality of Avaré, São Paulo State, Brazil. Rhabdias filicaudalis n. sp. differs from all other species by the combination of the following characters: straight body, truncated anterior end, six weakly developed lips arranged in two opposite groups of three, pre-equatorial vulva, oesophagus length/body length ratio $(\%)$ 4.9-7.5 (5.8 \pm 0.6$)$, nerve ring distance from anterior end/oesophagus length ratio (\%) 36.9-61.1 (49.8 \pm 6.4$)$, tail length/body length ratio (\%) 3.0-5.5 $(4.0 \pm 0.5)$, vulva distance from anterior end/body length ratio (\%) 39.9-51.7 $(45.9 \pm 3.5)$, and a cuticular filiform tail tip.
\end{abstract}

\section{Introduction}

Nematodes of the genus Rhabdias (Stilles and Hassall, 1905) can be found parasitizing amphibians and reptiles worldwide. From all species recorded parasitizing snakes, only four have been recorded in the Americas: Rhabdias eustreptos (MacCallum, 1921; Chitwood \& Chitwood, 1934), Rhabdias fuscovenosa (Railliet, 1899; Goodey, 1924), Rhabdias lamothei (Martínez-Salazar \& León-Règagnon, 2006) and Rhabdias vellardi (Pereira, 1928). Only R. vellardi has been recorded in Brazil, with reports in many snake species. Apart from the original description (Pereira, 1928), all publications are limited to reports of occurrence, with no new data on morphological aspects or life cycle. Rhabdias labiata has been reported in some papers but, according to Baker (1987), this species was synonymized with Acanthorhabdias acanthorhabdias.

During a survey of rhabdiasid nematodes in snakes from São Paulo State, Brazil, a Spilotes pullatus

\footnotetext{
*E-mail: thbarrella@gmail.com
}

(Linnaeus, 1758) specimen, infected with Rhabdias sp., was found. Nematodes did not match the data for $R$. vellardi or any other species of this genus previously described as parasites of snakes. The aim of the present study is to describe a new species of the genus Rhabdias.

\section{Materials and methods}

An adult male of S. pullatus, captured on 10 January 2006, in the municipality of Avaré, São Paulo State, Brazil was brought to the Centro de Estudos de Venenos e Animais Peçonhentos (CEVAP) at the Universidade Estadual Paulista (UNESP) in Botucatu, São Paulo State, Brazil. The snake died in captivity and necropsy revealed nematodes in the lungs $(n=168)$. Nematodes were fixed in alcohol-formalin-acetic acid (AFA) solution and transferred to $70 \%$ alcohol for further processing. Thirty specimens were cleared with lactophenol and analysed with a computerized system for image analysis (Qwin Lite 3.1, Leica Microsystems, Wetzlar, Germany). Measurements are reported as minimum-maximum (mean \pm standard deviation) and given in micrometres unless 
otherwise stated. Some specimens were placed in a $2.5 \%$ glutaraldehyde solution, with phosphate buffer $(0.15 \mathrm{M}$, $\mathrm{pH} 7.3$ ) for $24 \mathrm{~h}$ and transferred to $1 \%$ osmium tetroxide solution, with the same buffer, for $2 \mathrm{~h}$. Specimens were dehydrated through an ethanol series, critically point dried, then placed on a support and coated with a $20 \mathrm{~nm}$

A

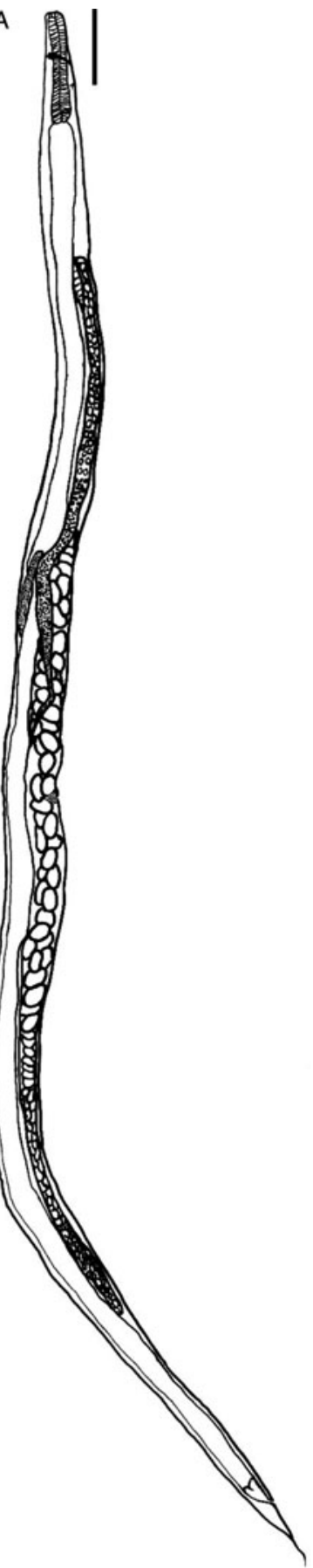

gold powder layer and analysed with a Philips MEV-SEM 515. Holotype and five paratypes are deposited in the Coleção Helmintológica of the Instituto Oswaldo Cruz (CHIOC), Rio de Janeiro State, Brazil. Paratypes are also deposited in the Coleção Helmintológica (CHIBB) of the Departamento de Parasitologia, Instituto de Biociências,
B

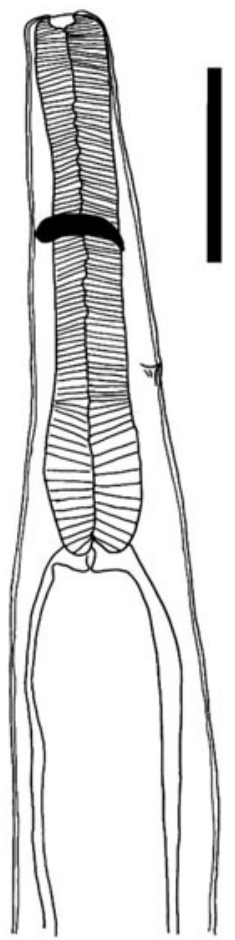

C

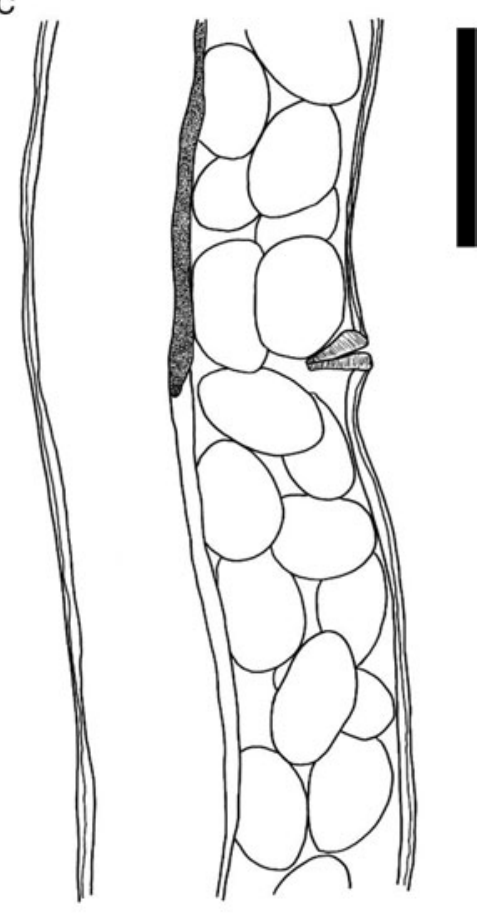

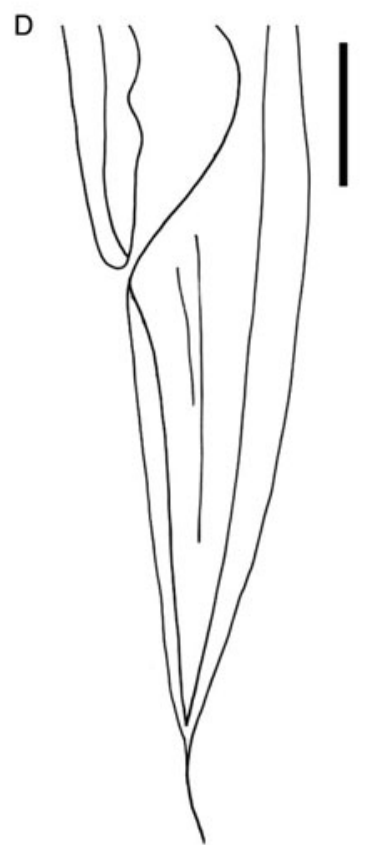

Fig. 1. Rhabdias filicaudalis n. sp. (Nematoda: Rhabdiasidae) from Spilotes pullatus (Serpentes: Colubridae). (A) Parasitic adult; (B) oesophagus; (C) vulva region; (D) tail. Scale bars: $A=200 \mu \mathrm{m}, \mathrm{B}=100 \mu \mathrm{m}, \mathrm{C}=100 \mu \mathrm{m}, \mathrm{D}=30 \mu \mathrm{m}$. 
Universidade Estadual Paulista, UNESP, Botucatu, São Paulo State, Brazil.

\section{Description}

Rhabdias filicaudalis $n$. $s p$.

Body straight, outer layers not swollen, fine transverse striations at the anterior and posterior ends, anterior end truncated, posterior end tapered with a thin filiform prolongation of the cuticle, oral opening surrounded by six weakly developed lips arranged in two opposite groups of three, buccal capsule cup-shaped in lateral view and round in apical view, oesophagus club-shaped, intestines with thick walls and filled with a brown content, slightly pre-equatorial vulva with indistinct lips, genital system amphidelphic with anterior and posterior ovaries overlapping at the vulva region, uteri filled with 30-40 eggs (figs $1-3$ ).

\section{Measurements}

Total body length 3.89-5.83 (4.94 \pm 0.46$)$ mm; width 129.7-262.4 (186.8 \pm 28.4$)$; buccal capsule 10.6-18.2 (14.2 \pm 1.8$)$ wide and 8.3-14.9 (10.6 \pm 1.4$)$ deep; oesophagus $250.6-316.1(285.8 \pm 16.6)$ in length with $25.2-$ 42.4 (33.6 \pm 3.2 ) width at the beginning, 33.9-48.7 (39.1 \pm 3.6$)$ width at the middle and 47.8-71.9 $(57.5 \pm 7.1)$ max. width at the posterior portion; nerve ring distance from the beginning of the oesophagus 105.6-176.6 (142.6 \pm 19.0$)$; distance of vulva from the anterior end 1693.4-2831.7 (2282.4 \pm 279.0$)$; tail length
145.2-262.2 (195.9 \pm 23.3 ); anterior oviduct loop distance to anterior end 502.4-1165.6 (855.3 \pm 147.7$)$; posterior oviduct loop distance to posterior end 649.1-1604.2 (1000.5 \pm 230.7); eggs $(n=50) 31.0-50.4$ (39.9 \pm 3.7$)$ wide and 55.2-86.2 (68.8 \pm 7.8$)$ long.

\section{Proportions (\%)}

Oesophagus length to total body length: 4.9-7.5 (5.8 \pm 0.6$)$; nerve ring distance from anterior end to oesophagus length: $36.9-61.1(49.8 \pm 6.4)$; tail length to total body length: $3.0-5.5(3.9 \pm 0.5)$; vulva distance from anterior end to total body length: 39.9-51.7 (45.9 \pm 3.5$)$.

\section{Taxonomic summary}

Type host and locality. Spilotes pullatus, from the municipality of Avaré, São Paulo State, Brazil $\left(48^{\circ} 55^{\prime} \mathrm{W}, 23^{\circ} 6^{\prime} \mathrm{S}\right.$, $766 \mathrm{~m}$ above sea level).

Site of infection. Lungs.

Specimens deposited. Holotype, five paratypes, parasitic adult females, deposited at the Coleção Helmintológica do Instituto Oswaldo Cruz (CHIOC) at the Fundação Instituto Oswaldo Cruz (FIOCRUZ), Rio de Janeiro, Rio de Janeiro State, Brazil, under the numbers CHIOC $35653 \mathrm{a}$ and $35653 \mathrm{~b}$, respectively. Other paratypes deposited at the Coleção Helmintológica do Instituto de Biociências de Botucatu (CHIBB) at the Instituto de Biociências de Botucatu, UNESP, Botucatu, São Paulo State, Brazil under the number 4755 .

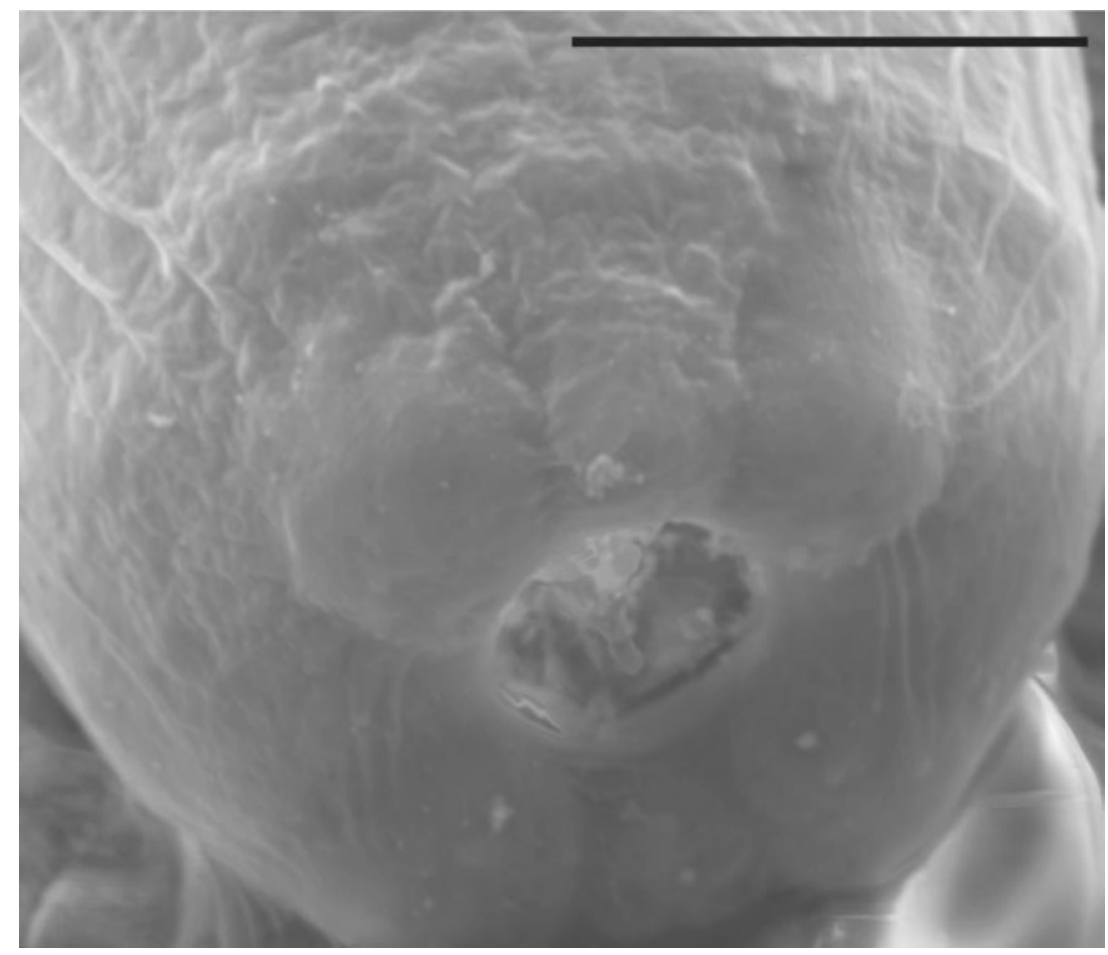

Fig. 2. Rhabdias filicaudalis n. sp. (Nematoda: Rhabdiasidae) from Spilotes pullatus (Serpentes: Colubridae): peribuccal papillae (scanning electron microscopy, scale bar $=20 \mu \mathrm{m})$. 


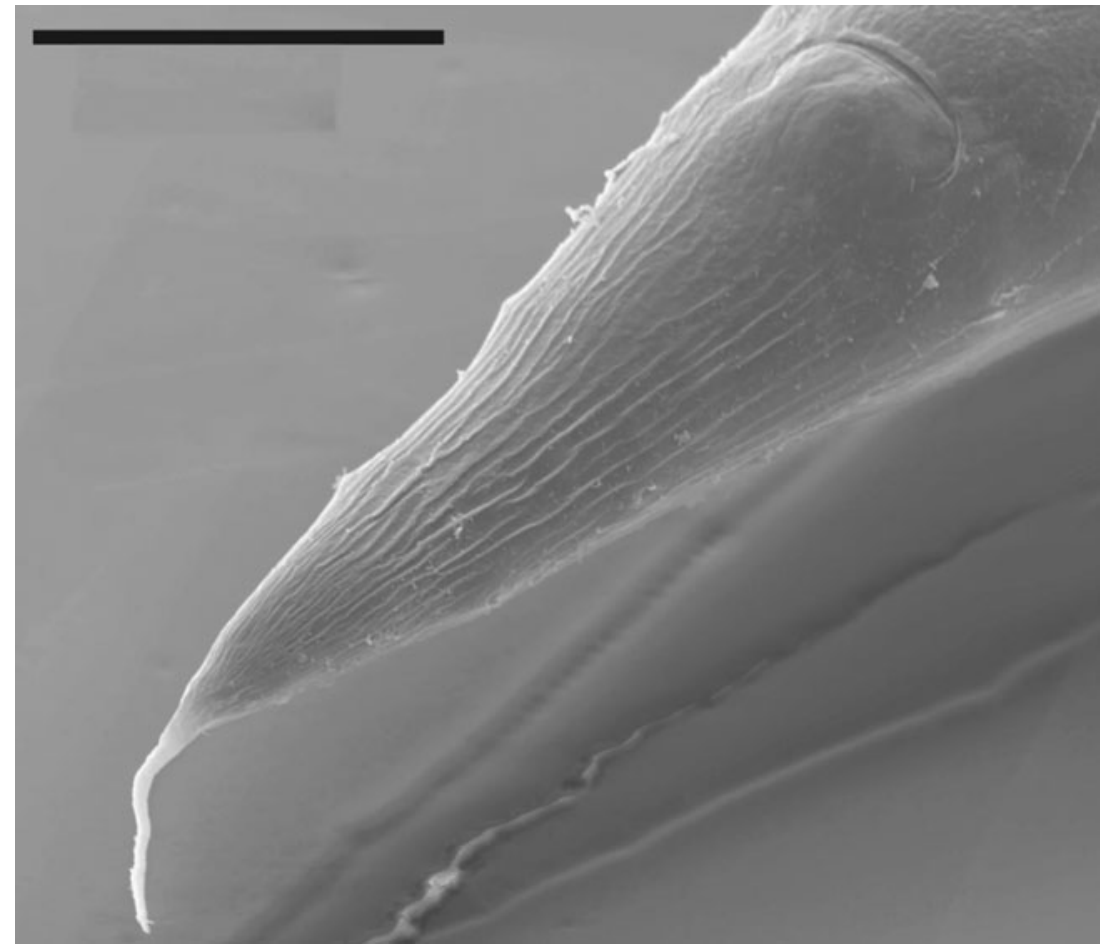

Fig. 3. Rhabdias filicaudalis n. sp. (Nematoda: Rhabdiasidae) from Spilotes pullatus (Serpentes: Colubridae): posterior end (scanning electron microscopy, scale bar $=50 \mu \mathrm{m}$ ).

Etymology. The new species was named in reference to the filiform prolongation of the cuticle at the tail.

Rhabdias filicaudalis n. sp. differs from all other species of this genus by the combination of the following characters: total body length $3.89-5.83 \mathrm{~mm}$, truncated anterior end, six weakly developed lips placed in two opposite groups of three, oesophagus length/total body length ratio $4.9-7.5 \%$, tail length/body length ratio $3.0-5.5 \%$, pre-equatorial vulva, short cone-shaped tail with a terminal filiform prolongation of the cuticle.

Species of the genus Rhabdias recorded in South America are Rhabdias androgyna (Kloss, 1974), Rhabdias elegans (Gutierrez, 1945), Rhabdias fuelleborni (Travassos, 1926), Rhabdias hermaphrodita (Kloss, 1971), Rhabdias mucronata (Schuurmans Stekhoven, 1952), Rhabdias truncata (Schuurmans Stekhoven, 1952) and Rhabdias vellardi. $R$. vellardi was recorded as a parasite of snakes, whereas the rest were recorded as parasites of amphibians.

Rhabdias fuelleborni is closely related to R. filicaudalis $\mathrm{n}$. $\mathrm{sp}$. according to the presence of six lips and pre-equatorial vulva. Rhabdias fuelleborni differs from $R$. filicaudalis $\mathrm{n}$. $\mathrm{sp}$. by total body length $(10-20 \mathrm{~mm}$ in R. fuelleborni vs. $3.89-5.83 \mathrm{~mm}$ in $R$. filicaudalis $\mathrm{n}$. sp.), oesophagus length (450-500 vs. $250.6-316.1$ in R. filicaudalis n. sp.), presence of an inflated corpus in $R$. fuelleborni and absence in $R$. filicaudalis n. sp., and host preference (amphibians vs. snakes).

Rhabdias mucronata and $R$. truncata could not be compared to $R$. filicaudalis $\mathrm{n}$. $\mathrm{sp}$. due to the fact that parasitic adults of these species are unknown.
Rhabdias filicaudalis $\mathrm{n}$. sp. differs from $R$. vellardi (the only other snake-parasitic Rhabdias species recorded in Brazil) by the presence of fine striations at anterior and posterior ends ( $R$. vellardi, according to the original description, has no striations on the cuticle), total body size (R. filicaudalis n. sp. $3.89-5.83 \mathrm{~mm}$ vs. $3.0-3.3 \mathrm{~mm}$ for $R$. vellardi), oesophagus length to total body length ratio (4.9-7.5\% in R. filicaudalis vs. $7.9-9.0 \%$ in $R$. vellardi), vulva distance from anterior end to total body length ratio (39.9-51.7\% in $R$. filicaudalis n.sp. and equatorial position (approximately $50 \%$ ) in R. vellardi).

Rhabdias agkistrodonis (Sharpilo, 1976), Rhabdias elaphe (Sharpilo, 1976), R. eustreptos, Rhabdias fuscovenosa (Railliet, 1899; Goodey, 1924), Rhabdias horigutii (Yamaguti, 1943), Rhabdias kurilensis (Sharpilo, 1976), Rhabdias lamothei (Martínez-Salazar \& León-Règagnon, 2006) and Rhabdias martinoi (Kurochkin et Gus'kov, 1963) are closely related to $R$. filicaudalis $\mathrm{n}$. $\mathrm{sp}$. according to host preference.

Rhabdias eustreptos, $R$. fuscovenosa, R. lamothei, R. kurilensis and $R$. martinoi differ from $R$. filicaudalis $\mathrm{n}$. sp. by vulva position (equatorial vs. pre-equatorial in $R$. filicaudalis $\mathrm{n}$. sp.). Rhabdias agkistrodonis differs from $R$. filicaudalis n. sp. by size and distribution of the lips, body width (slightly wider in R. agkistrodonis), buccal capsule width (16-23 vs. $8.3-14.9$ in $R$. filicaudalis n. sp.) and realm (Palaeartic vs. neotropical for $R$. filicaudalis n. sp.).

Rhabdias anolis is closely related to $R$. filicaudalis $\mathrm{n}$. $\mathrm{sp}$. according to the presence of six lips and pre-equatorial vulva. They differ according to the anterior end shape (rounded vs. truncated in R. filicaudalis n. sp.), total body 
length (4.6-7.4 vs. 3.89-5.83 in R. filicaudalis n. sp.) and host preference (lizards vs. snakes for $R$. filicaudalis n. sp.).

\section{Discussion}

The genus Rhabdias has been widely studied, but there are only a few publications with descriptions of species from South America. Recent publications involving studies of the genus Rhabdias in South America are limited to records of new hosts, and reports of known species and their pathological effects on hosts (Araújo et al., 1999; Boquimpani-Freitas et al., 2001; Silva et al., 2001, 2007; Luque et al., 2005; Santos et al., 2008).

Rhabdias filicaudalis n. sp. was found in S. pullatus, a snake species with a wide distribution, ranging from south of South America to north of Central America. This may indicate that $R$. filicaudalis $\mathrm{n}$. sp. has a wide geographical distribution, and more snake species as hosts.

Brazil has six large distinct biomes, hosting more than 750 species of amphibians and 630 species of reptiles (Brazilian Herpetological Society (SBH), 2008, www.sbherpetologia.org.br) with the potential to host species of the genus Rhabdias. It is reasonable to suggest that more species of the genus Rhabdias may be discovered and described, as well as other helminths.

\section{Acknowledgements}

We thank the Centro de Estudos de Venenos e Animais Peçonhentos (CEVAP-UNESP) which allowed us to work with the animals under their care, and the Fundação de Amparo à Pesquisa do Estado de São Paulo (FAPESP) for financial support (Process: 06/50 968-8).

\section{References}

Araújo, T., Moro, L., Lúcia, M., Golloubeff, M. \& Vasconcelos, A.C. (1999) Ocorrência de alguns endo e ectoparasitos no serpentário da UNIFENAS -
Universidade de Alfenas - MG. Brazilian Journal of Veterinary Research and Animal Science 36, 19-22.

Baker, M.R. (1987) Synopsis of the Nematoda parasitic in amphibians and reptiles. Memorial University of Newfoundland Occasional Papers in Biology 11, 325 pp.

Boquimpani-Freitas, L., Vrcibradic, D., Vicente, J.J., Bursey, C.R., Rocha, C.F.D. \& Van Sluys, M. (2001) Helminths of the horned leaf frog, Proceratophrys appendiculata, from southeastern Brazil. Journal of Helminthology 75, 233-236.

Luque, J.L., Martins, A.N. \& Tavares, L.E.R. (2005) Community structure of metazoan parasites of the yellow Cururu toad, Bufo ictericus (Anura, Bufonidae) from Rio de Janeiro, Brazil. Acta Parasitologica 50, 215-220.

Martínez-Salazar, E.A. \& León-Règagnon, V. (2006) Rhabdias lamothei n. sp. (Nematoda: Rhabdiasidae) from Leptodeira maculata (Colubridae) in Mexico, including new records of $R$. fuscovenosa (Railliet, 1899) Goodey, 1924. Zootaxa 1257, 27-48.

Pereira, C. (1928) Fauna helminthologica dos ophideos Brasileiros. Boletim Biologico de São Paulo 11, 13-22.

Santos, K.R., Takahira, R.K., Rall, V.L.M., Calderón, C., Sequeira, J.L. \& Silva, R.J. (2008) Pulmonary, microbiological and hematological changes in Crotalus durissus terrificus (Serpentes, Viperidae) parasitized by nematodes of the genus Rhabdias (Nematoda, Rhabdiasidae). Arquivo Brasileiro de Medicina Veterinária e Zootecnia 60, 667-674.

Silva, R.J., Barella, T.H., Nogueira, M.F. \& O'Dwyer, L.H. (2001) Frequency of helminths in Crotalus durissus terrificus (Serpentes, Viperidae) in captivity. Revista Brasileira de Parasitologia Veterinária 10, 91-93.

Silva, R.J., Nogueira, M.F., Barrella, T.H. \& Takahira, R.K. (2007) Frequency of rhabdiasid nematodes in wild Crotalus durissus terrificus (serpentes, viperidae) from Botucatu region, São Paulo state, Brazil. Journal of Venomous Animals and Toxins Including Tropical Diseases 13, 122-129. 